\title{
Overview of soft intelligent computing technique for supercritical fluid extraction
}

\author{
Sitinoor Adeib Idris ${ }^{1}$, Masturah Markom² \\ ${ }^{1}$ Faculty of Chemical Engineering, Universiti Teknologi MARA, Malaysia \\ ${ }^{1,2}$ Departement of Chemical and Process Engineering, Universiti Kebangsaan Malaysia, Malaysia
}

\begin{abstract}
Article Info
Article history:

Received May 8, 2019

Revised Jul 142019

Accepted Feb 11, 2020

Keywords:

Artificial technique

Hybrid

Neural network

Optimization

Smart system

ABSTRACT

Optimization of Supercritical Fluid Extraction process with mathematical modeling is essential for industrial applications. The response surface methodology (RSM) has been proven to be a useful and effective statistical method for studying the relationships between measured responses and independent factors. Recently there are growing interest in applying smart system or artificial technique to model and simulate a chemical process and also to predict, compute, classify and optimize as well as for process control. This system works by generalizing the experimental result and the process behavior and finally predict and estimate the problem. This smart system is a major assistance in the development of process from laboratory to pilot or industrial. The main advantage of intelligent systems is that the predictions can be performed easily, fast, and accurate way, which physical models unable to do. This paper shares several works that have been utilizing intelligent systems for modeling and simulating the supercritical fluid extraction process.
\end{abstract}

This is an open access article under the CC BY-SA license.

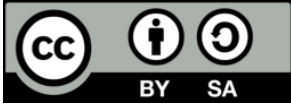

\section{Corresponding Author:}

Sitinoor Adeib Idris, Faculty of Chemical Engineering, Universiti Teknologi MARA, 40450, Shah Alam, Selangor, Malaysia.

Email: adeib@salam.uitm.edu.my

\section{INTRODUCTION}

Traditional computational approaches and methods could only model and analyze simple systems. Complex systems such as in machining, biology, medicine and similar fields often remained unsolvable to conventional mathematical and analytical methods. Assumptions and simplification of mathematical model are sometimes not reliable and many conventional mathematical models have been both challenging and impractical. Soft computing however, deals with imprecision, uncertainty, partial truth and approximation to achieve tractability, robustness and more importantly low solution cost. Figure 1 shows the available components of soft computing. There are five types which are neural networks, fuzzy systems, evolutionary computation, ideas about probabilities and swarm intelligence. This study is will focus on an overview of previous research applying some of the components such as neural networks, fuzzy systems, genetic algorithm and its hybrid in supercritical fluid extraction process.

Conventional techniques are largely based on formal logical systems and rely heavily on computeraided numerical analysis. Soft computing techniques are intended to complement each other. Hard computing schemes strive for accurateness and full truth whereas soft computing techniques exploit the given tolerance of imprecision, partial truth, and uncertainty for a particular problem or data. In overall, soft computing 
technique is similar and imitating the genetic processes more closely than the traditional technique. It applies the ability to learn, observe and memorize in a situation of full of factors and important data.

Whereas, hybrid intelligence systems deal with the integration of two or more of the technologies. The combined use of technologies has resulted in effective problem solving in comparison with each technology used individually and exclusively. As illustrated in Figure 2, each of these technologies individually and in combination can be employed to solve problems. For example, when neural network combines with fuzzy systems, a neuro-fuzzy hybrid will develop and when neural network and evolutionary algorithm combines, a neuro-evolutionary will be developed.

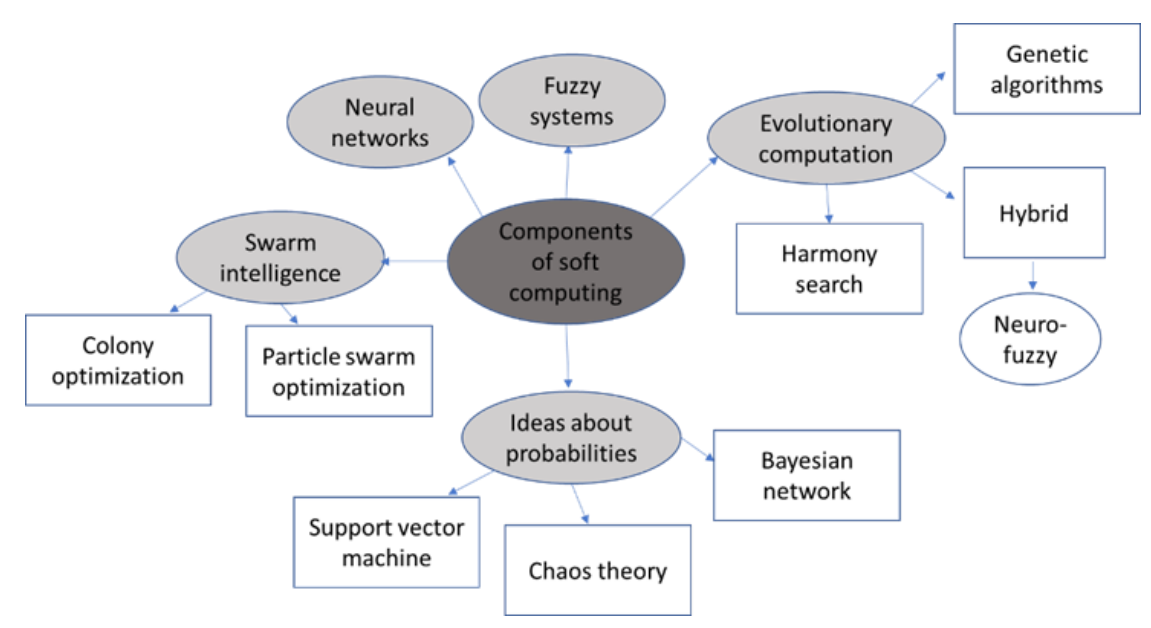

Figure 1. Components of soft computing [1]

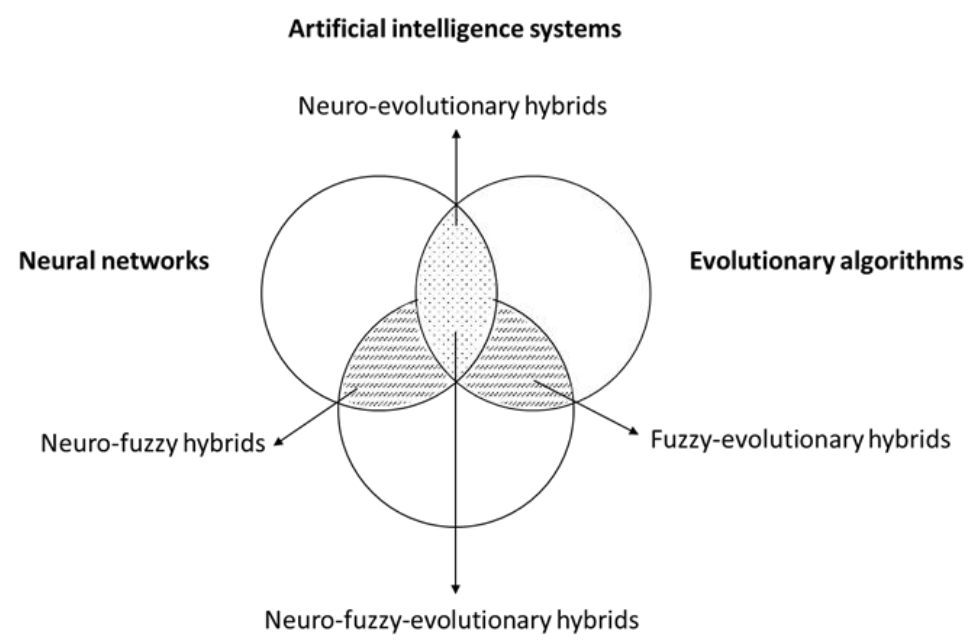

Fuzzy systems

Figure 2. Integration of neural networks, fuzzy systems and evolutionary algorithm technologies by [2]

\section{PREVIOUS STUDY APPLYING SOFT INTELLIGENT COMPUTING TECHNIQUE}

In order to develop a reliable model to represent the data, neural network have been applied to several supercritical fluid extraction processes in predicting yield of extraction [1-6] and solubility predictions [7-9]. Besides that, fuzzy systems also has been applied to determine the extractant quantities at desired temperatures and pressures [10].

There are several studies using a hybrid model combining ANN and FIS which is called as ANFIS to predict solubility [11] and mass of extract [12, 13]. Another type of hybrid is by combining ANN with a conventional mathematical model [14]. This type of hybrid was mainly to solve the black box issues of not understanding the process of SFE. By ANN-Mathematical model hybrid, one can solve the issue [15]. 
Some studies even compare the results of application of ANN and ANFIS in order to identify the best system that can represent the data and reliable for optimization process [16-19].

Genetic algorithm also one of the promising tools in optimization of SFE [20-24]. It has been applied in determining constants in mathematical model in order to minimize error between model results and experimental data [25]. It can also be used in generating the non-linear binary interaction parameter of the conventional mathematical model such as in Peng-Robinson equation [26].

\section{ARTIFICIAL NEURAL NETWORK (ANN) AND ADAPTIVE NEURO-FUZZY INFERENCE SYSTEM (ANFIS)}

Adaptive Neuro-Fuzzy Inference System (ANFIS) is considered as one type of hybrid model for optimization process since it combines the Artificial Neural Network (ANN) and Fuzzy Inference System (FIS) system. Table 1 describes the advantages and disadvantages applying ANN model independently.

Table 1. Advantages and limitations of ANN-based models [27]

\begin{tabular}{ll}
\hline \multicolumn{1}{c}{ Advantages } & \multicolumn{1}{c}{ Limitations } \\
\hline $\begin{array}{l}\text { Easy for correlation of data although absent of suitable } \\
\text { function }\end{array}$ & Hard to interpret and analyze the output \\
$\begin{array}{l}\text { The model can easily be developed and took less time to } \\
\text { be developed compared to other models }\end{array}$ & The training of the data might take much time, even days \\
$\begin{array}{ll}\text { No theoretical knowledge of process and literature } \\
\text { parameters needed to develop the model }\end{array}$ & $\begin{array}{l}\text { A large set of experimental data needed covering wide } \\
\text { operating conditions needed because of he training of an } \\
\text { ANN used the experimental data }\end{array}$ \\
$\begin{array}{ll}\text { It can handle noise, incomplete and inconsistent data } \\
\text { whenever the over-fitting is avoided }\end{array}$ & $\begin{array}{l}\text { The architecture depends on the variation of conditions } \\
\text { when trained and cannot be predicted }\end{array}$ \\
\hline
\end{tabular}

The 'black-box' nature of ANN models and unsatisfactory extrapolation by ANN models have led to the development of hybrid neural network models which combine ANNs with simple models. These are expected to perform better than ANNs in process identification tasks, since generalization and extrapolation are confined only to the uncertain parts of the process while the basic model is always consistent with first principles [28].

In a study on quercetin extraction from Rosa damascene Mill an experiment was conducted using a modified supercritical $\mathrm{CO}_{2}$ with ethanol as co-solvent [19]. The recovery of extraction was predicted using Adaptive neuro-fuzzy inference system (ANFIS) and Artificial neural network (ANN). The variables were translated into coded value of $-2,-1,0,+1$ and +2 . Table 2 shows the coded variables for this process. The coded variables are usually applied when RSM, ANN and ANFIS is going to be used as tools for optimization process.

Table 2. Uncoded and coded levels of independent variables used in the RSM, ANN and ANFIS

\begin{tabular}{ccccc}
\hline Coded variables & $\begin{array}{c}\text { Temperature, } \mathrm{T} \\
\left({ }^{\circ} \mathrm{C}\right)\end{array}$ & $\begin{array}{c}\text { Pressure, } \mathrm{P} \\
(\mathrm{MPa})\end{array}$ & $\begin{array}{c}\text { Dynamic time, } \mathrm{t} \\
(\mathrm{min})\end{array}$ & $\begin{array}{c}\text { Flow rate of } \mathrm{CO}_{2}, \\
\mathrm{Q}(\mathrm{ml} / \mathrm{min})\end{array}$ \\
\hline-2 & 35 & 10 & 40 & 0.3 \\
-1 & 40 & 15 & 60 & 0.6 \\
0 & 45 & 20 & 80 & 0.9 \\
+1 & 50 & 25 & 100 & 1.2 \\
+2 & 55 & 30 & 120 & 1.5 \\
\hline
\end{tabular}

Generally, ANFIS architecture consists of 5 layers as shown in Figure 3. The architecture of ANFIS in Figure 3 maps the inputs through input membership functions (MF) and fuzzy rules. Similarly, output mapping is done through output membership functions along with its fuzzy rules. The number of membership function assigned to each input variable is chosen by trial and error. Figure 3 shows the general architecture of ANFIS for SFE system.

The hybrid of a neural network and fuzzy logic in ANFIS makes it have both, low-level learning and computational power of neural network and advantages of high-level human like thinking of fuzzy systems. Therefore, this neuro-fuzzy model able to overcome their individual disadvantages and can complement each other [29]. 


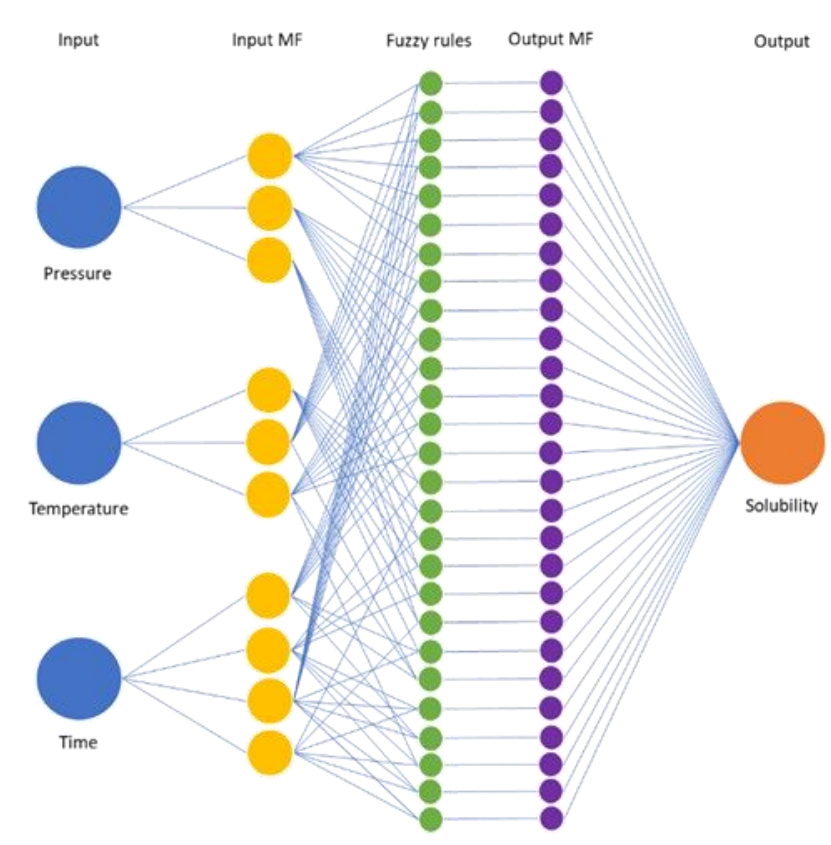

Figure 3. ANFIS architecture

\section{MATHEMATICAL MODEL-NEURAL NETWORK HYBRID}

Hybrid models can also be combining both physical laws and observed measurements and including all available knowledge of the process. This model can be arranged in series or in parallel. In the series approach, heuristic model estimates unmeasured process parameters of mathematical modeling such that the first principle constrains are satisfied. In the parallel approach, the hybrid model prediction is combination of the outputs of the mathematical and initial heuristic models thus residuals between the process and the mathematical model is compensated [27]. This type of hybrid can solve the black box issues of neural network where the knowledge of the process is lacking. When combining both, the model will become more reliable and can represents the data well.

A parallel hybrid model was developed by researchers from Iran [13] for prediction of Epigallocatechin gallate (EGCG) recovery of supercritical extraction which combines conventional mathematical modeling based on the differential mass balance in the solid and mobile phases with ANFIS (Figure 4). Using analytical model in this structure, the accuracy of ANFIS would be increased in nontraining domains. Additionally, ANFIS solves the problem of unknown analytical parameters. In other words, the hybrid model could simulate the extraction system with having any arbitrary value of adjustable parameters of mathematical modeling [27].

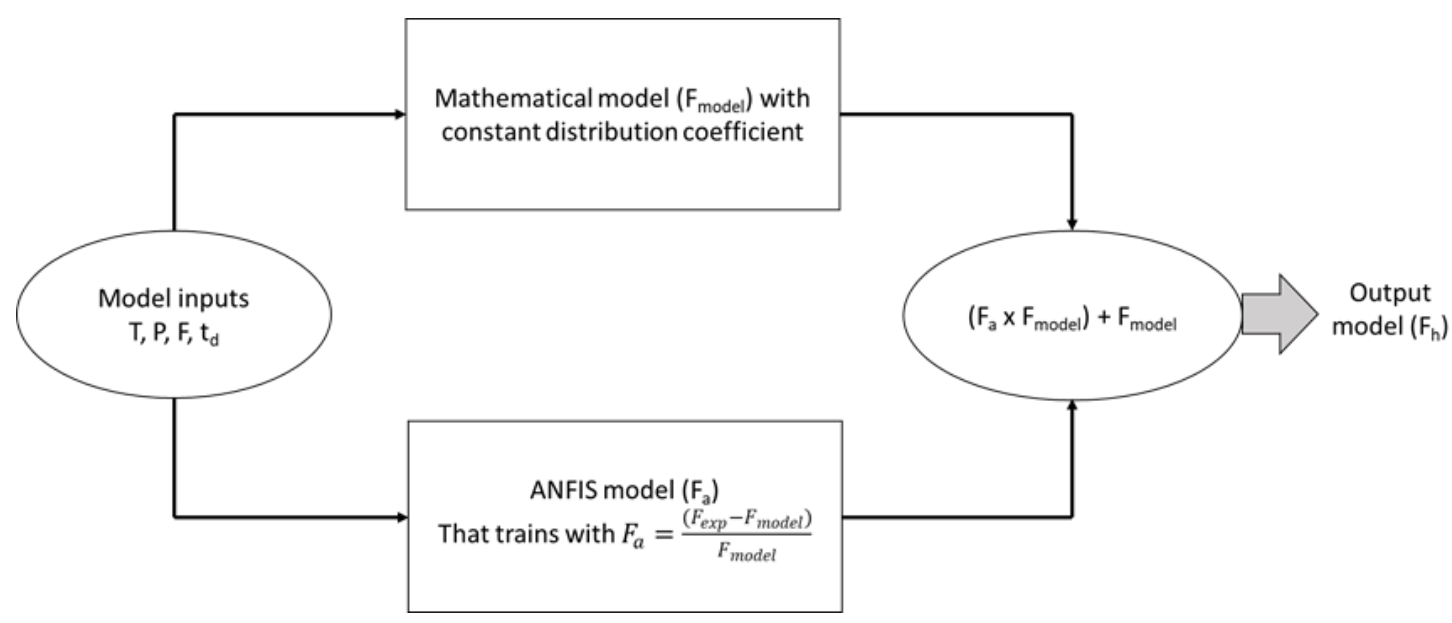

Figure 4. Parallel combination of mathematical model and ANFIS network in a hybrid structure by [15] 
In 2003, a group of researchers from Canada proposed a hybrid model of Radial Basis FunctionPeng Robinson (RBF-PR) model. The hybrid model was developed by first developing a simple RBF model. A simple RBF model consist of three inputs of $\mathrm{T}, \mathrm{p}$ and other factors with one output which is yield rate. This model has no knowledge on the whole process. To overcome the black box problem of the RBF model, the model is correlated with the Peng-Robinson equation becomes a hybrid RBF-PR model (Figure 5). In the Peng-Robinson equation of state, there is unknown interaction parameter $\mathrm{k}_{12}$, for a binary mixture, whereby the predicted solubility is sensitive. The $\mathrm{k}_{12}$ can be obtained from the physical property data for the mixture, but it requires trial and error process for obtaining it. Besides, the parameters were all temperature dependent which does not really fit the data compared to pressure. The proposed hybrid model by [30] can compensate the black box problem. It can fit the experiment data very well and also keep the physical meaning of the whole SFE process. The detailed description on previous research applying ANFIS and the hybrid of it for yield and solubility prediction is shown in Table 3.

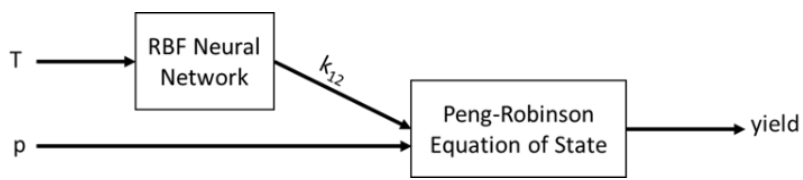

Figure 5. Schematic diagram of the proposed hybrid model by [31]

Table 3. Compilation of research applying hybrid model-ANFIS tools for predicting yield and solubility for SFE

\begin{tabular}{|c|c|c|c|c|c|}
\hline Model & Sample & Extract & Purpose & Remarks & References \\
\hline ANFIS & Solid compound & - & $\begin{array}{l}\text { Estimation } \\
\text { of solubility }\end{array}$ & $\begin{array}{l}\text { The input parameters: critical pressure, acentric } \\
\text { factor, critical temperature and molar volume as } \\
\text { well as the operating temperature and pressure } \\
\text { The output parameter: solubility }\end{array}$ & [13] \\
\hline ANFIS & $\begin{array}{l}\text { Pimpinella } \\
\text { anisum L. seed }\end{array}$ & Seed oil & $\begin{array}{l}\text { Prediction } \\
\text { mass of } \\
\text { extract }\end{array}$ & $\begin{array}{l}\text { The input parameters: pressure, solvent mass } \\
\text { flow rate, and extraction time } \\
\text { The output parameter: mass of extract } \\
\text { Within } 369 \text { observations, } 277 \text { observations were } \\
\text { used to train the network, and the remaining } 92 \\
\text { observations were kept for further testing the } \\
\text { developed network }\end{array}$ & [14] \\
\hline ANFIS & $\begin{array}{l}\text { Glycyrrhiza } \\
\text { glabra L. }\end{array}$ & $\begin{array}{l}\text { Glycyrrhizic } \\
\text { acid (GA) }\end{array}$ & $\begin{array}{l}\text { Modeling } \\
\text { the recovery } \\
\text { of extraction }\end{array}$ & $\begin{array}{l}\text { Independent variables: dynamic time }(\mathrm{t}) \text {, } \\
\text { pressure }(\mathrm{P}) \text {, temperature }(\mathrm{T}) \text { and flow rate of } \\
\text { SCCO2 }(\mathrm{Q}) \text {. } \\
\text { Dependent variable: Recovery of GA }\end{array}$ & [19] \\
\hline ANFIS & Pomegranate & Seed oil & $\begin{array}{l}\text { Simulation } \\
\text { of oil yield }\end{array}$ & $\begin{array}{l}\text { Comparing the data obtained between ANN and } \\
\text { ANFIS model }\end{array}$ & [20] \\
\hline ANFIS & $\begin{array}{l}\text { Rosa } \\
\text { damascene Mill }\end{array}$ & Quercetin & $\begin{array}{l}\text { Modeling } \\
\text { the recovery } \\
\text { of extraction }\end{array}$ & $\begin{array}{l}\text { Independent variables: dynamic time }(\mathrm{t}) \text {, } \\
\text { pressure }(\mathrm{P}) \text {, temperature }(\mathrm{T}) \text { and flow rate of } \\
\mathrm{SCCO} 2(\mathrm{Q}) \text {. } \\
\text { Dependent variable: Recovery } \\
\text { Comparing the data obtained between ANFIS } \\
\text { and RSM } \\
\text { Refer Table } 2\end{array}$ & [21] \\
\hline $\begin{array}{l}\text { RBF-PR } \\
\text { hybrid }\end{array}$ & Benzoic acid & - & $\begin{array}{l}\text { Modeling } \\
\text { the yield }\end{array}$ & $\begin{array}{l}\text { Input parameters: Temperature, pressure and } \\
\text { one other factors } \\
\text { Output parameter: yield rate } \\
\text { Mathematical model: Peng-Robinson model } \\
\text { Refer Figure } 5\end{array}$ & [31] \\
\hline $\begin{array}{l}\text { Mathematical } \\
\text { model- } \\
\text { ANFIS } \\
\text { hybrid }\end{array}$ & Green tea & $\begin{array}{l}\text { Epigallocatechin } \\
\text { gallate (EGCG) }\end{array}$ & $\begin{array}{l}\text { Modeling } \\
\text { the recovery } \\
\text { of extraction }\end{array}$ & $\begin{array}{l}\text { Input parameters: dynamic time, pressure, } \\
\text { temperature and flow rate of SC-CO2 } \\
\text { Output parameter: model output } \\
\text { Mathematical model: differential mass balance } \\
\text { in the solid and mobile phases model } \\
\text { Refer Figure } 4\end{array}$ & [15] \\
\hline
\end{tabular}

\section{GENETIC ALGORITHM (GA)}

Genetic algorithms are a class of optimization programs that can handle complicated problems. They consist of a random-search method, that made efficient by using explorative search. The method resembles evolutionary development in nature, using "mutation" and "mating". In contrast to expert systems no heuristic knowledge is applied other than the ultimate goal [32]. 
In 2016, a group of researchers in Iran did an optimization of essential oil extraction from Launaea acanthodes Boiss using genetic algorithm [33]. In their study, they applied the hybrid ANN-GA methodology whereby, ANN model was used as the fitness function, which measures the quality of individuals in the population. The model was then used to obtain the optimal operation conditions, such as pressure, temperature, flow rate, and co solvent besides determining the maximum extraction yield of essential oil from $L$. acanthodes. The general procedure to apply GA for most system was as shown in Figure 6. Table 4 has the description of previous application of GA in SFE for various materials.

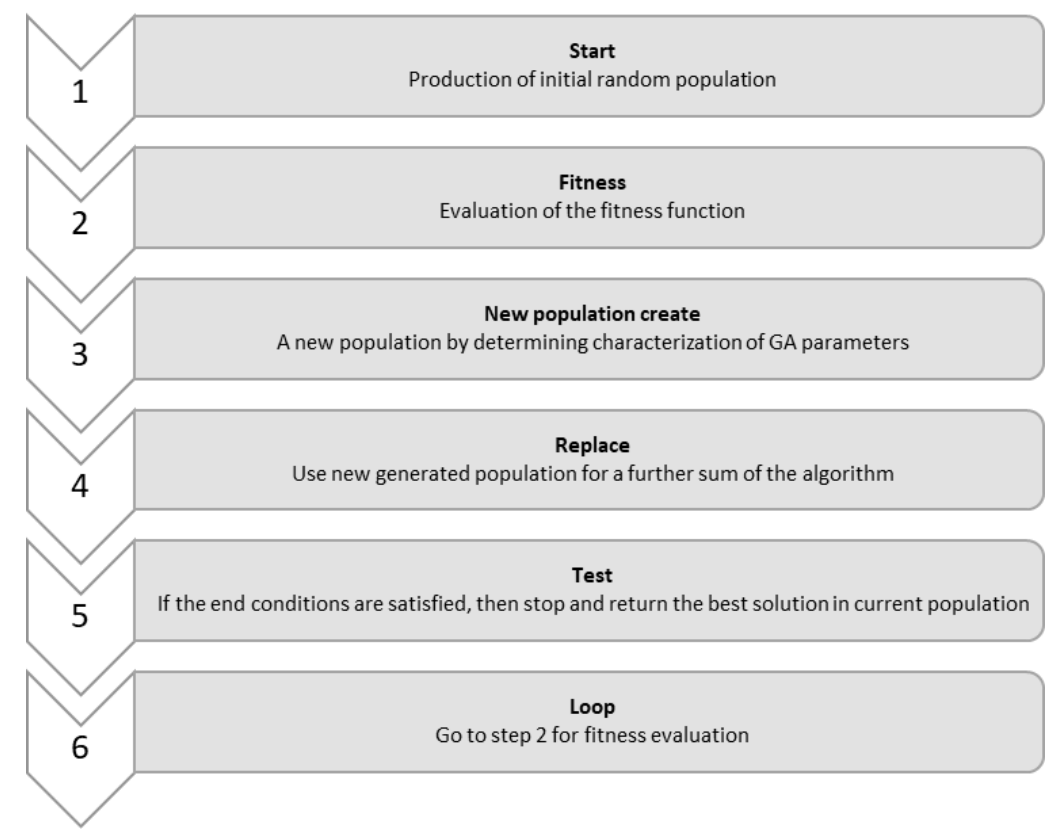

Figure 6. Genetic algorithm procedure for optimization process

Table 4. Genetic algorithm application for optimization in SFE

\begin{tabular}{|c|c|c|c|c|}
\hline Sample & Extract & Purpose & Remarks & References \\
\hline $\begin{array}{l}\text { Launaea } \\
\text { acanthodes Boiss }\end{array}$ & Essential oil & Optimization of extraction yield & $\begin{array}{l}\text { ANN model was used as the fitness } \\
\text { function, which measures the quality of } \\
\text { individuals in the population }\end{array}$ & [33] \\
\hline Soybean meal & Isoflavone & Optimization of profitability & $\begin{array}{l}\text { The objective function of this study is } \\
\text { profitability which is more } \\
\text { comprehensive than the cumulative } \\
\text { isoflavone production rate }\end{array}$ & {$[24]$} \\
\hline Green tea & $\begin{array}{l}\text { Epigallocatechin } \\
\text { gallate }\end{array}$ & Optimization of extraction recovery & $\begin{array}{l}\text { The fitness function for this study is } \\
\text { extraction recovery }\end{array}$ & {$[25]$} \\
\hline $\begin{array}{l}\text { Macela flowers } \\
\text { (Achyrocline } \\
\text { satureioides) }\end{array}$ & $\begin{array}{l}\text { Bioactive } \\
\text { compound }\end{array}$ & Determination of constant & $\begin{array}{l}\text { Adjustable parameters, } \mathrm{K} \text {, a, and } \mathrm{b} \text {, were } \\
\text { determined by criteria that the sum of the } \\
\text { squares of the difference between the } \\
\text { experimental extraction yield and the } \\
\text { predicted extraction yield by the model } \\
\text { should be minimized }\end{array}$ & {$[28]$} \\
\hline Solid compounds & - & $\begin{array}{l}\text { Optimization of the radius of } \\
\text { influence of FIS }\end{array}$ & $\begin{array}{l}\text { The Genetic Algorithm (GA), which is } \\
\text { an optimization algorithm, was } \\
\text { implemented to measure the optimum } \\
\text { value of radius of influence of FIS } \\
\text { parameter }\end{array}$ & {$[13]$} \\
\hline Ferulaga angulate & - & Optimization of yield & $\begin{array}{l}\text { The ANN model coupled with genetic } \\
\text { algorithm (GA) was used to generate the } \\
\text { optimal value }\end{array}$ & [34] \\
\hline Benzoic acid & - & Dynamic optimization of process & $\begin{array}{l}\text { A dynamic optimization model for } \\
\text { supercritical fluid extraction is proposed } \\
\text { by combining a transformation based } \\
\text { genetic algorithm } \\
\text { and the Peng-Robinson equation of state }\end{array}$ & {$[35]$} \\
\hline
\end{tabular}




\section{CONCLUSION}

Overall, the application of smart system or artificial technique to model and simulate a chemical process has been done in SFE process together with RSM method. Smart system models generalize the experimental result and present process behavior and finally predict and estimate problem. The model can be applied individually or by combining two or more models called as hybrid to achieve the best estimation and prediction data. The appropriate model is beneficial in the development of new products by saving experimental time and cost. However, research and study on dynamic process for SFE using artificial technique is lacking and the area is recommended for further research.

\section{ACKNOWLEDGEMENTS}

The authors would like to thank Ministry of Higher Education (MOHE) and Universiti Teknologi MARA, for providing financial support. Moreover, the authors would like to thank Universiti Kebangsaan Malaysia for providing research facilities.

\section{REFERENCES}

[1] A. B. Kurhe, S. S. Satonkar, P. B. Khanale, and S. Ashok, "Soft Computing and its applications," BIOINFO Soft Comput., vol. 1, no. 1, pp. 5-7, 2011.

[2] S. Rajasekaran and G. A. V Pai, Neural Networks, Fuzzy Systems and Evolutionary Algorithms: Synthesis and Applications. PRENTICE-HALL OF INDIA, 2017.

[3] B. Pavlic, O. Bera, S. Vidovic, L. Ilic, and Z. Zekovic, "Extraction kinetics and ANN simulation of supercritical fluid extraction of sage herbal dust," J. Supercrit. Fluids, vol. 130, pp. 327-336, 2017.

[4] P. Mitra, P. C. Barman, and K. S. Chang, "Coumarin Extraction from Cuscuta reflexa using Supercritical Fluid Carbon Dioxide and Development of an Artificial Neural Network Model to Predict the Coumarin Yield," Food Bioprocess Technol., vol. 4, no. 5, pp. 737-744, 2011.

[5] J. Yin, Q. Xu, W. Wei, and A. Wang, "Experiments and Numerical Simulations of Supercritical Fluid Extraction for Hippophae rhamnoides L Seed Oil Based on Artificial," Ind. Eng. Chem. Res, vol. 44, pp. 7420-7427, 2005.

[6] L. M. Salleh, S. E. R. Abel, G. Zahedi, R. A. Rahman, H. M. Nasir, and S. A. S. Faua'ad, "Optimization of supercritical carbon dioxide extraction of quercus infectoria oil," J. Teknol., vol. 74, no. 7, pp. 79-86, 2015.

[7] P. Davoodi, S. M. Ghoreishi, and A. Hedayati, "Optimization of supercritical extraction of galegine from Galega officinalis L.: Neural network modeling and experimental optimization via response surface methodology," Korean J. Chem. Eng., vol. 32, no. 4, pp. 1-12, 2016.

[8] S. M. Ghoreishi and E. Heidari, "Extraction of Epigallocatechin-3-gallate from green tea via supercritical fluid technology: Neural network modeling and response surface optimization," J. Supercrit. Fluids, vol. 74, pp. 128-136, 2013.

[9] A. M. Abbas Karim and A. K. Mutlag, "Comparison Study for the Solubility Prediction of Phenanthrene in Supercritical CO2 entraind with n- pentane when using Equation of State and Artificial Neural networks," Emirates J. Eng. Reseacrh, vol. 16, no. 1, pp. 81-90, 2011.

[10] A. Aminian, "Estimating the solubility of different solutes in supercritical CO2 covering a wide range of operating conditions by using neural network models," J. Supercrit. Fluids, vol. 125, pp. 79-87, 2017.

[11] B. Vaferi, M. Karimi, M. Azizi, and H. Esmaeili, "Comparison between the artificial neural network, SAFT and PRSV approach in obtaining the solubility of solid aromatic compounds in supercritical carbon dioxide," $J$. Supercrit. Fluids, vol. 77, pp. 44-51, 2013.

[12] S. Sheu, M. Jang, C. Wang, C. Tsai, and Y. Hsueh, "Detc2008-49182 Simulation and Application of Fuzzy Theory for Supercritical Carbon," in Proceedings of the ASME 2008, 2008.

[13] M. R. Dadkhah et al., "Prediction of solubility of solid compounds in supercritical $\mathrm{CO}_{2}$ using a connectionist smart technique," J. Supercrit. Fluids, vol. 120, pp. 181-190, 2017.

[14] M. Davoody, G. Zahedi, M. Biglari, M. A. A. Meireles, and A. Bahadori, "Expert and gray box modeling of highpressure liquid carbon dioxide extraction of Pimpinella anisum L. seed," J. Supercrit. Fluids, vol. 72, pp. 213-222, 2012.

[15] E. Heidari and S. M. Ghoreishi, "Prediction of supercritical extraction recovery of EGCG using hybrid of Adaptive Neuro-Fuzzy Inference System and mathematical model," J. Supercrit. Fluids, vol. 82, pp. 158-167, 2013.

[16] S. X. Yang, J. Zeng, H. Li, X. Yuan, and M. Meng, "Modeling of Supercritical Fluid Extraction Using an Integrated Soft Computing and Conventioanl Approach," in Proceedings of the 2003 IEEE International Conference on Robotics, Intelligent Systems and Signal Processing, pp. 668-673, 2003.

[17] S. X. Yang, H. Li, and J. Shi, "Modeling of Supercritical Fluid Extraction by Neural Networks," Intell. Autom. Soft Comput., vol. 9, no. 1, pp. 3-12, 2003.

[18] J. Sargolzaei, M. Haghighi Asl, and A. H. Moghaddam, "Prediction of Super Critical Oil Extraction Yield Using Single and Combined Intelligent Systems," Glob. Perspect. Artif. Intell., vol. 1, no. 2, pp. 15-22, 2013.

[19] A. Hedayati and S. M. Ghoreishi, "Artificial Neural Network and Adaptive Neuro-Fuzzy Interface System Modeling of Supercritical CO<inf $>2<$ inf $>$ Extraction of Glycyrrhizic Acid from Glycyrrhiza glabra L," Chem. Prod. Process Model., vol. 11, no. 3, 2016. 
[20] J. Sargolzaei and A. H. Moghaddam, "Predicting the yield of pomegranate oil from supercritical extraction using artificial neural networks and an adaptive-network-based fuzzy inference system," Front. Chem. Sci. Eng., vol. 7, no. 3, pp. 357-365, 2013.

[21] S. M. Ghoreishi, A. Hedayati, and S. O. Mousavi, "Quercetin extraction from Rosa damascena Mill via supercritical CO2: Neural network and adaptive neuro fuzzy interface system modeling and response surface optimization," $J$. Supercrit. Fluids, vol. 112, pp. 57-66, 2016.

[22] E. Rahimi, J. M. Prado, G. Zahedi, and M. A. A. Meireles, "Chamomile extraction with supercritical carbon dioxide: Mathematical modeling and optimization,” J. Supercrit. Fluids, vol. 56, pp. 80-88, 2011.

[23] G. Sodeifian, S. A. Sajadian, and N. Saadati Ardestani, "Experimental optimization and mathematical modeling of the supercritical fluid extraction of essential oil from Eryngium billardieri: Application of simulated annealing (SA) algorithm," J. Supercrit. Fluids, vol. 127, no. April, pp. 146-157, 2017.

[24] K. Lummaetee, H. M. Ku, W. Wongrat, and A. Elkamel, "Optimization of supercritical fluid extraction of isoflavone from soybean meal," Can. J. Chem. Eng., vol. 95, no. 6, pp. 1141-1149, 2017.

[25] S. M. Ghoreishi and E. Heidari, "Extraction of epigallocatechin gallate from green tea via modified supercritical CO2: Experimental, modeling and optimization," J. Supercrit. Fluids, vol. 72, pp. 36-45, 2012.

[26] G. Zahedi, A. Elkamel, A. Lohi, and T. Hatami, "Optimization of supercritical extraction of nimbin from neem seeds in presence of methanol as co-solvent," J. Supercrit. Fluids, vol. 55, no. 1, pp. 142-148, 2010.

[27] A. K. Verma, Process Modelling and Simulation in Chemical, Biochemical and Environmental Engineering. CRC Press, 2014.

[28] T. Hatami, R. N. Cavalcanti, T. M. Takeuchi, and M. A. A. Meireles, "The Journal of Supercritical Fluids Supercritical fluid extraction of bioactive compounds from Macela (Achyrocline satureioides) flowers: Kinetic, experiments and modeling," J. Supercrit. Fluids, vol. 65, pp. 71-77, 2012.

[29] H. Li and S. X. Yang, "Modelling of supercritical fluid extraction by hybrid Peng-Robinson equation of state and genetic algorithms," Biosyst. Eng., vol. 86, no. 1, pp. 17-25, 2003.

[30] D. C. Psichogios and L. H. Ungar, "A hybrid neural network???first principles approach to process modeling," AIChE J., vol. 38, no. 10, pp. 1499-1511, 1992.

[31] J. Zeng and S. X. Yang, "Optimal Control of Supercritical Fluid Extraction with a Hybrid Model," in Proceedings of the 2003 IEEE International Symposium on Intelligent Control, 2003.

[32] G. Kateman, "Data Handling in Science and Technology," in Data Handling in Science and Technology, L. M. C. Buydens and P. J. Schoenmakers, Eds. Elsevier Ltd, 1993, pp. 281-310.

[33] G. Sodeifian, S. A. Sajadian, and N. Saadati Ardestani, "Optimization of essential oil extraction from Launaea acanthodes Boiss: Utilization of supercritical carbon dioxide and cosolvent," J. Supercrit. Fluids, vol. 116, pp. 46-56, 2016.

[34] G. Sodeifian, S. A. Sajadian, and N. Saadati Ardestani, "Evaluation of the response surface and hybrid artificial neural network-genetic algorithm methodologies to determine extraction yield of Ferulago angulata through supercritical fluid," J. Taiwan Inst. Chem. Eng., vol. 60, pp. 165-173, 2016.

[35] S. X. Yang, J. Zeng, and G. Wang, Extraction Using Dynamic Genetic Algorithm Based Optimisation, vol. 38, no. 1. IFAC, 2003.

\section{BIOGRAPHIES OF AUTHORS}

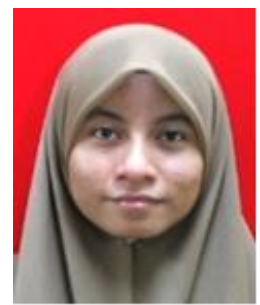

Sitinoor Adeib Idris received her bachelor's and master's degrees in chemical engineering from Universiti Teknologi MARA (UiTM), Shah Alam, Selangor, Malaysia. She is a PhD student at the Department of Chemical Engineering and Process, Faculty of Engineering and Built Environment, at Universiti Kebangsaan Malaysia (UKM), Bangi, Selangor, Malaysia. Her research is in the field of supercritical fluid extraction.

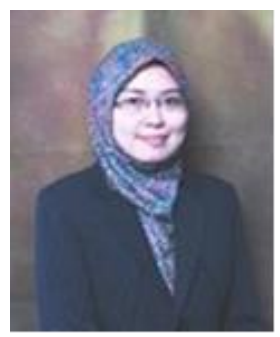

Masturah Markom is an associate professor of Chemical Engineering at the Department of Chemical Engineering and Process, UKM. She received her PhD in 2007 and master's degrees in chemical engineering from Universiti Malaya (UM) in 1998. Her research interest are separation technology and supercritical fluid extraction. 